\title{
Energylab Nordhavn: An integrated community energy system towards green heating and e-mobility
}

Wang, Jiawei; You, Shi; Zong, Yi; Træholt, Chresten

Published in:

Proceedings of 2017 IEEE Transportation Electrification Conference and Expo,

Link to article, DOI:

10.1109/ITEC-AP.2017.8080846

Publication date:

2017

Document Version

Peer reviewed version

Link back to DTU Orbit

Citation (APA):

Wang, J., You, S., Zong, Y., \& Træholt, C. (2017). Energylab Nordhavn: An integrated community energy system towards green heating and e-mobility. In Proceedings of 2017 IEEE Transportation Electrification Conference and Expo, (pp. 1-6). IEEE. https://doi.org/10.1109/ITEC-AP.2017.8080846

\section{General rights}

Copyright and moral rights for the publications made accessible in the public portal are retained by the authors and/or other copyright owners and it is a condition of accessing publications that users recognise and abide by the legal requirements associated with these rights.

- Users may download and print one copy of any publication from the public portal for the purpose of private study or research.

- You may not further distribute the material or use it for any profit-making activity or commercial gain

- You may freely distribute the URL identifying the publication in the public portal 


\title{
EnergyLab Nordhavn: An integrated community energy system towards green heating and e-mobility
}

\author{
Jiawei Wang, Shi You, Yi Zong, Chresten Træholt \\ Department of Electrical Engineering \\ Technical University of Denmark \\ Copenhagen, Denmark \\ jiawang@elektro.dtu.dk, sy@elektro.dtu.dk, yizo@elektro.dtu.dk, ctr@elektro.dtu.dk
}

\begin{abstract}
This paper analyzes the green potential of a newly developed urban community, i.e., Nordhavn, in Copenhagen, Denmark from a planning perspective, wherein the energy sector of power, heat and transportation will be developed as an integrated energy system solution. Based on an hour-by-hour analysis wherein the generation and demand in each energy sector are balanced, the analysis explains how different levels of penetration of centralized heat pumps (HPs) and electric vehicles (EVs) would influence the energy performance of this integrated community energy system. The performance of the integrated energy system is evaluated from the perspectives of annual fuel consumption, electricity import, system cost and $\mathrm{CO}_{2}$ emission, etc.
\end{abstract}

Keywords-EV smart charging; heat pump; integrated community energy system; Nordhavn; renewable energy

\section{INTRODUCTION}

The adoption of renewable energy is increasing worldwide in order to mitigate climate change, decrease $\mathrm{CO}_{2}$ emissions and reduce dependence on fossil fuels [1-4]. Denmark has a leading position in energy strategies and aims to build a fossil fuel independent society with a high security of energy supply by 2050 [5]. In order to target the $100 \%$ renewable energy goal, different energy systems, i.e. power, heat and transport, are required to be managed in an integrated way. The connection among the energy systems could enhance the system flexibility and enable a higher penetration of renewables [6], [7].

Besides a high penetration of $40 \%$ wind power in Danish electricity consumption, district heating $(\mathrm{DH})$ is also playing an important role in the current energy system, where around $50 \%$ of heat production is from renewables, with over $95 \%$ share from biomass [8]. Combined heat and power (CHP) plants are the main generation units in current Danish $\mathrm{DH}$ system and can also provide flexibility to the power system. Additionally, electrification of $\mathrm{DH}$ through centralized heat pumps (HPs) can potentially increase the profits of DH operation and the penetration level of renewables [9]. Moreover, the concept of 4th Generation DH (4GDH) is proposed in Denmark, which aims to reduce the heat loss through Low Temperature DH (LTDH) and increase the renewable energy penetration by acting as a flexible load of the power system through CHP plants, HPs, heat storage, etc. [10].
The ambitious energy goal also entails the increasing share of renewable energy in final energy consumptions. Especially, a greater share of electric vehicles (EVs) is expected in Danish transport sector [11]. Acting as a flexible load and storage of the power system, EV can mitigate the fluctuation of renewables [12]. Additionally, EV can act as a generation unit through vehicle-to-grid (V2G) technology, which can provide multiple ancillary services to the power system, e.g. frequency regulation [13], [14]. Moreover, the EV users' maximum profit during the charging is studied with multiple charging strategies [15], and congestion problem in distribution system solved by V2G services is studied in [16]. Therefore, replacing the fossil fuel by renewables in the transport system requires not only economic incentives but also a well-designed plan of the integrated community energy system [17].

Taking good care of the excess production of electricity caused by wind power and CHP plants is another major challenge encountered by Denmark. Danish wind power will reach $50 \%$ of electricity consumption by 2020 and the high fluctuation of wind will cause electricity export when demand is low. Similarly, the electricity production by CHP may exceed the power demand when heat generation is very high. Though excess electricity may not lead to reliability problem in current Danish power system when there are strong crossborders ties to neighbor countries, it will achieve less profit and more $\mathrm{CO}_{2}$ emissions [18]. Therefore, technologies like electrically driven HPs, are more and more recognized due to their high efficiency and the potential of building a flexible coupling between the heat system and the power system.

Copenhagen Nordhavn area is a demonstration of future dense and integrated energy system [19]. It will be supplied by LTDH and buildings will meet the Building Regulation 2020 (BR20) where the heat consumption for both space heating $(\mathrm{SH})$ and domestic hot water (DHW) is low [20]. In addition, the $40 \mathrm{MW}$ offshore wind farm, Middelgrunden, has the potential to supply the electricity in Nordhavn area [21]. Moreover, EV charging stations are expected to be built in center Nordhavn which could provide fast charging [22].

This paper aims to build a future energy solution for Nordhavn area, with an integrated portfolio of biomass CHP plants, wind power, electrically driven HPs and EVs, which would meet the energy demand in electricity, heat and transport 
system. The main contribution is to provide a guideline for an hourly integrated plan of a future renewable integrated community energy system in Copenhagen, for pursuing the ambitious energy goal, and to investigate the potential of replacing the CHP plant with centralized HPs in future DH system, and replacing the fossil fuel driven cars with EVs. In the second part of this paper, the assumptions applied to the modelling software EnergyPLAN are introduced. In case studies, the system performance is evaluated with hourly base for different HP and EV penetration levels, from the perspectives of annual fuel consumption, electricity import, system cost and $\mathrm{CO}_{2}$ emissions.

\section{Algorithm}

\section{A. Data assumptions}

The EnergyPLAN software is chosen to study the Nordhavn energy system in this paper. It is a simulation tool that can apply the modelling of an integrated electrical power, heat and transport system in a regional and national level. The analysis of energy balance can be carried out hourly and annually from both technical and economic aspects. The inputs of the model are described as below.

1) Demand overview: Heat demand in Nordhavn area is supplied with $\mathrm{DH}$ and predicted by assuming all buildings will tend to comply with the BR20 requirement in the future, therefore a yearly need of $20 \mathrm{kWh} / \mathrm{m}^{2}$ for $\mathrm{DHW}$ and $3 \mathrm{kWh} / \mathrm{m}^{2}$ for $\mathrm{SH}$ is expected [20]. The total Nordhavn floor area is expected to be $776000 \mathrm{~m}^{2}$ including Marmormolen, Århusgadekvarteret, Sundmolen, Trælastholmen and Levantkaj Vest neighborhoods [23]. Henceforth, the predicted annual heat demand is around $D M_{h t}=18 \mathrm{GWh}$. Additionally, the annual electricity demand is predicted to be around twice of the heat demand, $D M_{\text {ele }}=35 \mathrm{GWh}$ [23]. The transport demand $D M_{\text {tran }}$ is predicted according to the number of private cars. Since around $40 \%$ of the 10000 residents and employees in Nordhavn are expected to drive $10000 \mathrm{~km}$ per year, the total transport demand with all petrol and EV cars is expected to be $25 \mathrm{GWh} /$ year and 6GWh/year, respectively [24-26].

2) Demand distribution profiles prediction: The hourly distribution of heat consumption is collected from [27], which is a combination of hourly SH and DHW profiles. The hourly distribution of electricity consumption in Nordhavn, $D_{\text {ele }}$, is an area aggregation of commercial, residential and school load profiles in all neighborhoods [28],

$$
D_{\text {ele }}=\sum_{j=1}^{3} \sum_{i=1}^{5}\left(p_{j} \cdot A_{i, j}\right)
$$

where, $p_{j}$ is the hourly power distribution of load type $j$, which is one of the residential load (multi-family apartments), commercial load (restaurants and offices) and school load type. $A_{i, j}$ is the area of load type $j$ in each neighborhood $i$. The hourly driving pattern $D_{E V}$ of private cars is collected from travel schedule of Department of Transport, UK [29] and assumed to be the same as the Danish transport demand.

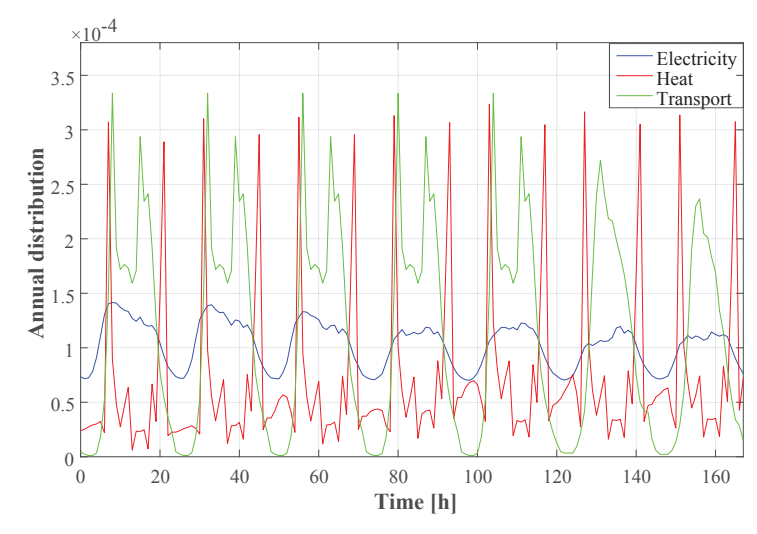

Fig. 1. Demand distribution of one week

Therefore, the predicted hourly demand distribution of heat, electricity and transport for one typical week (Monday to Sunday) is shown in Fig. 1. It shows the hourly probability distribution of the demand over a year for one week. It indicates that the power profile is a combination of commercial, residential and school load during the weekday, where the peak demand spreads over the morning and evening period. While at the weekend, the power profile is dominated by residential load where peak demand occurs during the evening. The heat profile includes peaks in the morning and evening when the DHW demand is high for showering and cooking. For the transport demand, also peaks occur in the morning and evening of the weekdays, representing the rush hours when people drive to work and back to home.

3) External power grid: It is assumed that the heat demand in Nordhavn area is only supplied by the local CHP plant while the electricity demand is satisfied by both CHP and the external power grid. The fuel distribution of the import electricity is determined and assumed as the one for Danish power system, which is shown in Fig. 2 (data from [30], [31]). Accordingly, the $\mathrm{CO}_{2}$ emission from the external grid is included to evaluate the whole system emission but not included in the emission cost.

4) EV smart charging profile: The $N_{E V}$ number of EVs is assumed to have a total battery capacity of $E_{b a t}=30$. $N_{E V} \mathrm{kWh}$, with a maximum charging power of $P_{\text {chargmax }}=$ $3.7 \cdot N_{E V} \mathrm{~kW}$ (with $16 \mathrm{~A}, 230 \mathrm{~V}$ connection) [32]. The smart charging of EVs aims to minimize the consumers' cost of EV charging given the electricity price and driving pattern, with a planning duration of one day,

$$
\min \sum_{k=1}^{N} P_{c h, k} \cdot Q_{k} \cdot E V_{\text {chargp }, k}
$$

where, at hour $k, P_{c h, k}$ is the aggregated charging power of $\mathrm{EVs}, Q_{k}$ is the electricity price collected from ELSPOT dayhead market in NordPool, $N$ is the number of hours of one day. The EV aggregated charging probability $E V_{\text {chargp }, k}$ is related to $\mathrm{EV}$ driving pattern, $D_{E V, k}$, which is the probability of cars that are used for driving shown in Fig. 1. It can be obtained 


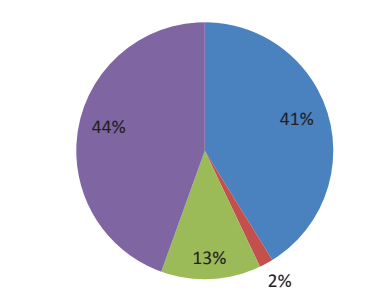

$\backsim$ Coal $\backsim$ Oil $\backsim$ Gas $\backsim$ Waste and biomass

(a)

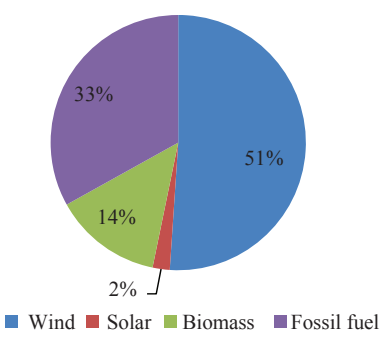

(b)
Fig. 2. External power grid (a) Fuel distribution of conventional power plants (b) Fuel distribution of electricity generation

with the following equation by assuming that all parked EVs are connected to charging stations at hour $k$ :

$$
E V_{\text {chargp }, k}=1-\frac{D_{E V, k}}{\max \left(D_{E V}\right)}
$$

The constraints of the optimization problem are expressed as below:

$$
\begin{aligned}
& P_{\text {ch }, k} \cdot E V_{\text {chargp }, k} \leq P_{\text {chargmax }} \\
& E_{\text {min }}-E_{\text {ini }} \leq \sum_{k=1}^{N}\left(P_{\text {ch }, k} \cdot E V_{\text {chargp }, k} \cdot \eta_{c h}\right. \\
& \left.-E V_{\text {drive }, k} \cdot \eta_{c h}^{2}\right) \\
& \sum_{k=1}^{N}\left(P_{c h, k} \cdot E V_{\text {chargp }, k} \cdot \eta_{c h}-E V_{\text {drive }, k} \cdot \eta_{c h}^{2}\right) \\
& \quad \leq E_{\text {max }}-E_{\text {ini }} \\
& P_{\text {ch, }, k} \cdot E V_{\text {chargp }, k} \geq 0
\end{aligned}
$$

where, $E_{i n i}$ is the initial energy of the battery at the beginning of one day, $E_{\text {min }}=0.1 \cdot E_{\text {bat }}$ and $E_{\max }=0.9 \cdot E_{b a t}$ are the minimum and maximum operational energy of the battery, respectively, $E V_{\text {drive }}$ is the driving power from grid side and $\eta_{c h}=0.9$ is the EV charging and discharging efficiency. The battery energy is updated with Eq. (5), every 24 hours after the optimization. Then the optimized charging of EV for the next day, $m+1$, is implemented again following Eq. (2), Eq. (3) and Eq. (4).

$$
\begin{aligned}
E_{i n i, m+1}=E_{\text {ini,m }}+\sum_{k=1}^{N}( & P_{\text {ch, }, k} \cdot E V_{\text {chargp }, k} \\
& \left.-E V_{\text {drive }, k} \cdot \eta_{c h}\right) \cdot \eta_{c h}
\end{aligned}
$$

The optimization results of hourly discrete EV charging profile, together with driving profile and price signals of one day are shown in Fig. 3. The dashed lines indicate the trend of variation. The results show that the EV charging periods are typically during $0 \mathrm{~h}-6 \mathrm{~h}, 13-14 \mathrm{~h}$ and $22 \mathrm{~h}-24 \mathrm{~h}$ when the driving power is low and the charging probability is high. Additionally, EV charging also locates in the low electricity price period for minimizing the charging payment of customers, e.g. 0-6h and 12-14h.

\section{B. Cost functions}

The total annual cost of the integrated energy system $C_{\text {tot }}$, includes the investment cost $C_{I}$, fixed operation and maintenance (OM) cost $C_{O M}$ and variable cost $C_{V}$ of $N_{g e n}$

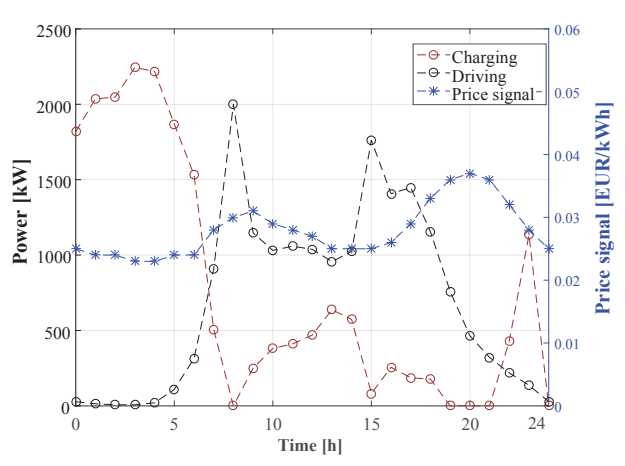

Fig. 3. EV charging, driving pattern and price signal of one day

number of generation units, fuel cost $C_{F}$ and $\mathrm{CO}_{2}$ emission cost $C_{C_{2}}$ of $M_{f l}$ number of fuels, and external grid cost $C_{E G}$ during $K$ hours of a year, where the investment cost is expressed as below,

$$
C_{I, i}=\frac{P_{i} \cdot a_{i} \cdot i_{n}}{1-\left(1+i_{n}\right)^{-n}}
$$

where, $P_{i}$ is the installation capacity of the generation unit $i$, $a_{i}$ is the investment cost coefficient, $i_{n}=0.03$ is the interest rate and $n$ is the lifetime of investment. Additionally, $C_{O M, i}=$ $C_{I, i} \cdot b_{i}$, where $b_{i}$ is the OM cost coefficient. $C_{V, i}=E L_{i} \cdot g_{i}$, where $E L_{i}$ is the electrical energy generation and $g_{i}$ is the variable cost coefficient. $C_{F, j}=E_{j} \cdot c_{j}$, where $E_{j}$ is the total energy consumption of fuel type $j$ and $c_{j}$ is the fuel cost coefficient. $C_{C O_{2}, j}=E M_{j} \cdot d_{j}$, where $E M_{j}$ is the local $\mathrm{CO}_{2}$ emission of fuel type $j$ and $d_{j}$ is the emission cost coefficient. $C_{E G, k}=P_{e, k} \cdot e_{k}$, where $P_{e, k}$ is the power export to (negative value) or import from the external grid (positive value), $e_{k}$ is the electricity price of the external grid at hour $k$.

Therefore, the total annual cost of the integrated community energy system can be represented as,

$$
\begin{aligned}
C_{\text {tot }}= & \sum_{i=1}^{N_{\text {gen }}}\left(C_{I, i}+C_{O M, i}+C_{V, i}\right)+\sum_{j=1}^{M_{f l}}\left(C_{F, j}+C_{C O_{2}, j}\right) \\
& +\sum_{k=1}^{K} C_{E G, k}
\end{aligned}
$$

The values assigned to the parameters are collected from [33], which is a prediction of year 2020 shown in TABLE I and TABLE II.

\section{The integrated energy system model in EnergyPLAN}

Based on the inputs introduced above, the hourly planning of the integrated energy system for a whole year will be developed, where the power, heat and transport demand will be balanced with different generation units for each hour.

TABLE I

PARAMETERS FOR COST FUNCTION

\begin{tabular}{cccc}
\hline Generation type & $a_{i}[\mathrm{kEUR} / \mathrm{kW}]$ & $b_{i}[\%]$ & $g_{i}[\mathrm{EUR} / \mathrm{MWh}]$ \\
\hline CHP & 1.2 & 3.75 & 2.7 \\
HP & 3.43 & 2 & 0.27 \\
\hline
\end{tabular}


TABLE II

PARAMETERS FOR FUEL CONSUMPTION

\begin{tabular}{ccccc}
\hline Parameters & Biomass & Petrol & Coal & Natural gas \\
\hline$c_{j}[\mathrm{EUR} / \mathrm{GJ}]$ & 7.3 & 16.1 & - & - \\
$\mathrm{CO}_{2}$ emission $[\mathrm{kg} / \mathrm{GWh}]$ & 0 & 74 & 95 & 56.7 \\
\hline
\end{tabular}

Typically, at hour $k$, the electrical and heat power balancing equations for the integrated energy system are shown as,

$$
\begin{aligned}
& \sum_{i=1}^{N_{g e n}} P_{e l e, i, k}+P_{e, k}=D_{e l e, k} \cdot D M_{e l e}+D_{E V, k} \cdot D M_{\text {tran }} \\
& \sum_{i=1}^{N_{g e n}} P_{h t, i, k}=D_{h t, k} \cdot D M_{h t} \\
& 0 \leq\left|P_{\text {ele }, i, k}\right| \leq P_{i} \\
& P_{h t, i, k}=\eta_{p t h, i} \cdot P_{\text {ele }, i, k}
\end{aligned}
$$

where, $P_{\text {ele,i }}$ and $P_{h t, i}$ are the electrical and heat power generation of local generation unit $i$, respectively. $\eta_{p t h, i}$ is the efficiency of power to heat conversion of generation unit $i$. Additionally, for generation unit like HPs, $P_{\text {ele }, i, k}$ is negative for being an electrically driven heat production unit.

Moreover, for each hour $k$, the fuel consumption $E_{k, j}$ of fuel type $j$, is evaluated by considering both the local and external energy system, namely,

$$
\begin{aligned}
& E_{k, j}=\sum_{j}^{J}\left(\frac{P_{e l e, k, j}}{\eta_{e l e, j}}+\frac{P_{e, k, j}}{\eta_{e x t, j}}\right), \\
& j \in\{\text { biomass, coal, oil, natural gas }\}
\end{aligned}
$$

where, $\eta_{e l e, j}$ and $\eta_{\text {ext }, j}$ are the energy efficiency of local and external power grid, respectively. In this paper, $\eta_{e x t, j}$ is following the proportion shown in Fig. 2.

In this paper, the regulation strategy implemented in EnergyPLAN is to meet the heat demand firstly, since the CHP plant and HP are assumed to be the only heat generation units in local Nordhavn area and no storage or external system is used for balancing the heat system. The production priority is assumed as fully use of the heat capacity of CHP plants first, then the one for HPs [34]. The planning results will be evaluated based on the annual fuel consumption, electricity import, systems cost and $\mathrm{CO}_{2}$ emission.

\section{CASE STUdies}

\section{A. System configurations}

The configuration of the integrated community energy system in Nordhavn implemented is shown in Fig. 4. It illustrates that the system is a combination of power, heat and transport, where the generation units are local CHP and HPs, the primary energy is from both fossil fuel and renewables. Typically, the energy connection units among the integrated energy system are CHP which satisfies both of the power and heat demand, HP which consumes electricity to generate heat and EV charging stations which utilize electricity to satisfy driving demand. The DH system has a heat loss of $15 \%$, the power and heat efficiency of the biomass CHP is $29 \%$ and $64 \%$, respectively, and the HP's coefficient of performance (COP) is 3 [35].

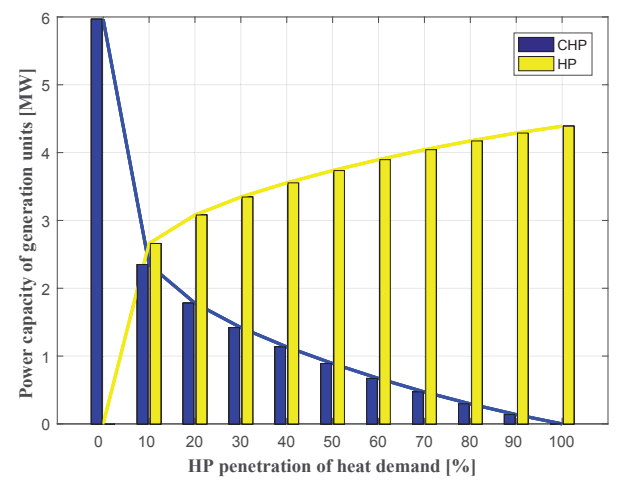

Fig. 5. CHP and HP power capacity with HP penetrations

\section{B. Case 1: DH penetrated with CHP and HPS}

In this case, the transport demand is only penetrated with petrol fueled cars. Additionally, CHP and centralized HPs are operated for meeting the power and heat demand. Different percentages of heat demand supplied by HPs are fulfilled by regulating the power capacity of CHP and HPs as shown in Fig. 5, where the total heat capacity is the same.

The results of annual fuel consumption, electricity import, systems cost and $\mathrm{CO}_{2}$ emission with different HP penetrations are shown in Fig. 6 and Fig. 7, respectively. It shows that, with a higher HP penetration, since the local CHP cannot satisfy the heat demand, a greater electricity import is needed to drive the HPs to produce heat. Consequently, the share of wind and solar power from the external grid is increasing, with a constant COP of the HPs, the electricity import has a linear increasing performance. Additionally, the efficiency of electricity production from biomass CHP is only $29 \%$ while the one from biomass and fossil fuels in the external grid is $56 \%$. Therefore, with a constant proportion of fuel distribution in the external grid, the fuel consumption of biomass and fossil fuels is decreasing with a linear behavior. However, the annual cost increases up to 4527 kEUR when HP penetration is $10 \%$, then drops lower than the one with 100\% CHP generation when HP penetration is more than $90 \%$. The reason is that when the HP penetration increases, there is a trade off between the electricity trading in the external grid, fixed and variable cost of HP and CHP plant, and the fuel cost.

\section{Case 2: CHP penetrated with HPs and EVs}

In case 2, the transport demand from petrol fueled cars is replaced by EVs in order to reduce the fossil fuel consumption. Therefore, the annual fuel consumption, electricity import, system cost and $\mathrm{CO}_{2}$ emissions with transport demand satisfied by different $\mathrm{EV}$ penetrations and different HP penetrations, are shown in Fig. 8 and Fig. 9, respectively.

Fig. 8 illustrates that with an increasing EV penetration from $0 \%$ to $100 \%$, the annual fuel consumption of biomass and fossil fuel has a linear decreasing. This is due to the higher efficiency of electricity production and the higher share of renewable in the external grid as stated before. Additionally, a higher penetration of EV requires a higher electricity import 


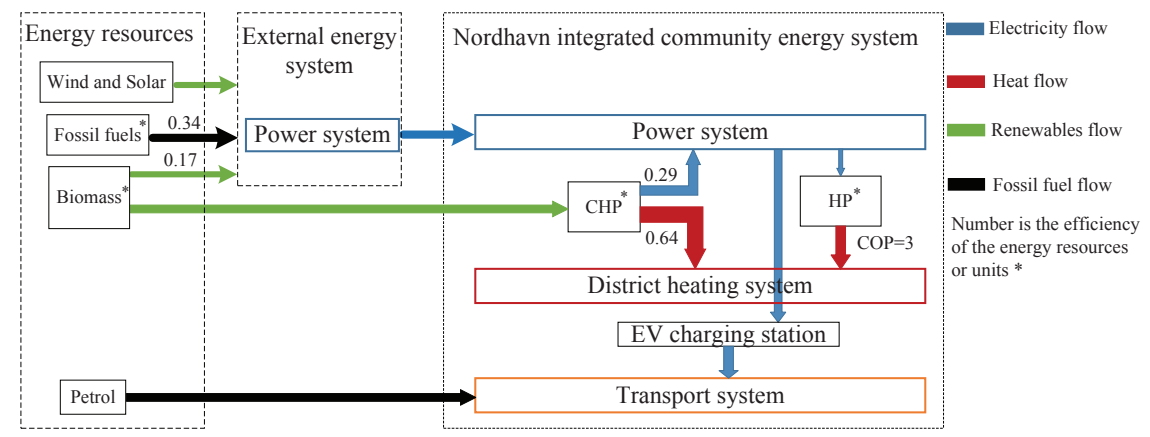

Fig. 4. Configuration of integrated community energy system in Nordhavn

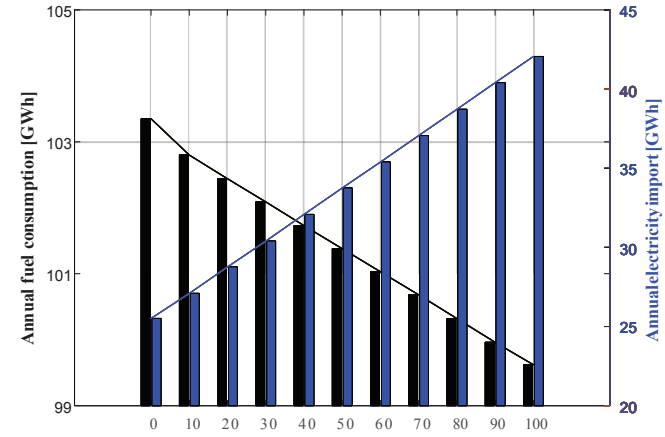

HP penetration of heat demand [\%]

Fig. 6. Annual fuel consumption and electricity import with HP penetrations

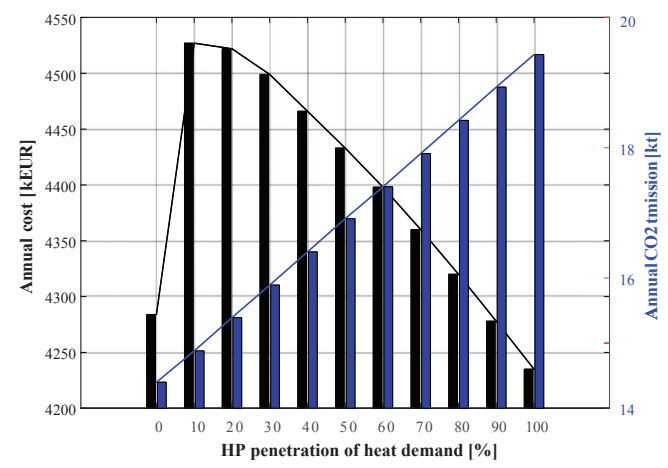

Fig. 7. Annual systems cost and $\mathrm{CO}_{2}$ emission with $\mathrm{HP}$ penetrations

since the CHP capacity can hardly satisfy the demand in the power system with EV integration.

Additionally, as shown in Fig. 9, the annual cost is decreasing with a higher EV penetration. This is due to the investment cost of traditional and EV cars are not included in this study. Therefore, a higher EV penetration leads to a higher amount of electricity energy trade in the electricity market, a lower fuel cost and $\mathrm{CO}_{2}$ emission cost, and in total a lower annual cost. Similarly, the increasing share of renewables in the total fuel consumption results in a lower $\mathrm{CO}_{2}$ emission, when the EV penetration increases.

Fig. 10 shows the normalized values of the four performances compared with the current system without EV or HP.

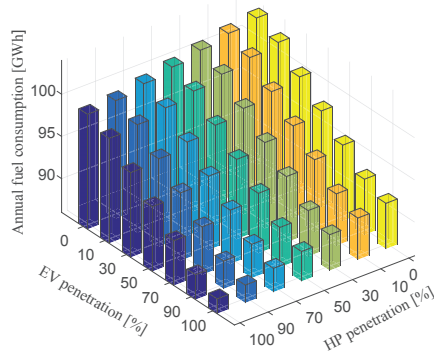

(a)

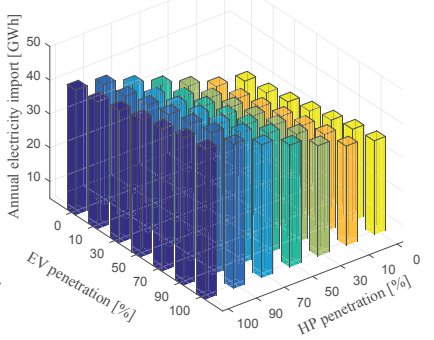

(b)
Fig. 8. With PV and EV penetration (a) annual fuel consumption (b) annual electricity import

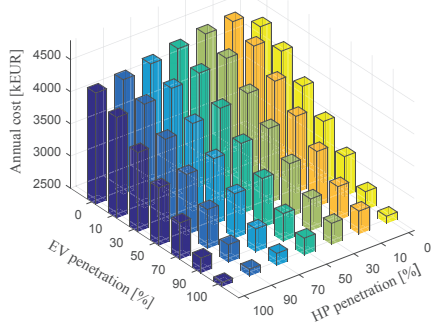

(a)

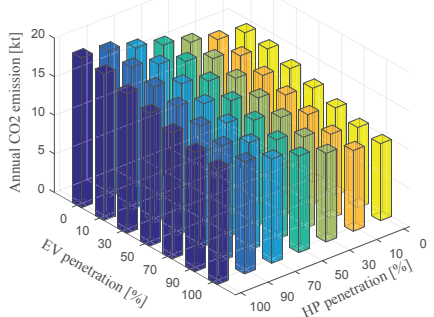

(b)
Fig. 9. With PV and EV penetration (a) annual system cost (b) annual $\mathrm{CO}_{2}$ emission

It indicates that only with $0 \% \mathrm{HP}$ and $100 \% \mathrm{EV}$, the system will result in a lower annual cost, $\mathrm{CO}_{2}$ emission and fuel consumption compared with the current system.

\section{CONCLUSIONS}

In this paper, an integrated community energy system of power, heat and transport systems in Copenhagen Nordhavn area, is modelled in EnergyPLAN. Results derived from an hourly based simulation of the system with varying penetration levels of HPs and EVs indicate a large potential to pursue the Danish goal of $100 \%$ renewable energy system. One of the indicator is by having electrically driven HPs in the Nordhavn system, the wind power penetration in the external grid could be greater and the energy efficiency of power and heat system 


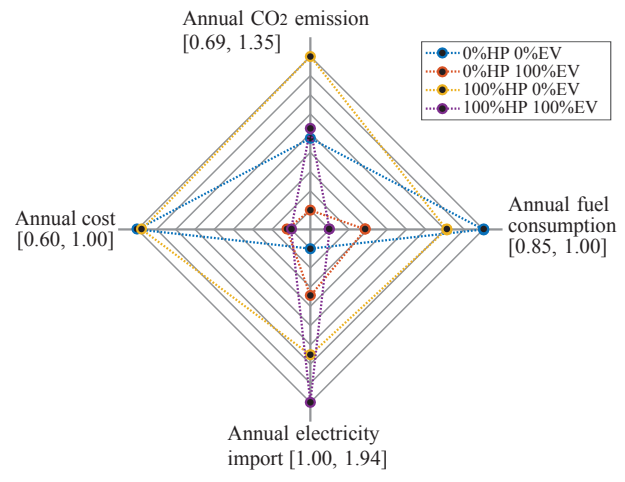

Fig. 10. Comparison of different EV and HP penetrations

could be improved. A high penetration of more than $90 \%$ of HPs has the potential of achieving lower annual cost than the current system.

Additionally, the connection between the power system and transport system by means of EVs may contribute to both a higher penetration of renewables and a profitable solution. One of the prerequisites of achieving such an outcome is to have smart charging, which minimizes the charging cost of EVs. Together with the tax reduction policy for EVs in Denmark, the integration of EVs in transport system may play an important role in the future integrated community energy system.

For the future work, the proportion of fuel types imported from the external grid could be considered as non-constant in order to increase the accuracy of modeling. Also, the impact of $\mathrm{V} 2 \mathrm{G}$ technology on the smart charging strategy is worthy of study. At the implementation stage, the influence of a higher penetration of EVs on frequency and voltage of the distribution system and a higher penetration of heat pumps on DH networks shall be considered.

\section{REFERENCES}

[1] "Overview of european union climate and energy policies," Ea Energy Analysis, Copenhagen, Denmark, Tech. Rep., Jan. 2012.

[2] D. Gielen, D. Saygin, and N. Wagner, "Renewable energy prospects: United states of america, remap 2030 analysis," IRENA, Abu Dhabi, Tech. Rep., 2015.

[3] Z. Liu, D. Guan, D. Crawford-Brown, Q. Zhang, K. He, and J. Liu, "Energy policy: A low-carbon road map for china," Nature, vol. 500 , no. 7461, pp. 143-145, 2013.

[4] “2015 energy white paper," Department of Industry and Science, Australia government, Australia, Tech. Rep., 2015.

[5] "Energy strategy 2050 - from coal, oil and gas to green energy," The Danish Ministry of Climate and Energy, Denmark, Tech. Rep., 2015.

[6] S. You, L. Jin, J. Hu, Y. Zong, and H. W. Bindner, "The danish perspective of energy internet: from service-oriented flexibility trading to integrated design, planning and operation of multiple cross-sectoral energy systems," Zhongguo Dianji Gongcheng Xuebao, vol. 35, no. 14, pp. 3470-3481, 2015.

[7] P. Meibom, K. B. Hilger, H. Madsen, and D. Vinther, "Energy comes together in denmark: the key to a future fossil-free danish power system,' IEEE Power and Energy Magazine, vol. 11, no. 5, pp. 46-55, Sept.-Oct. 2013.

[8] "Energistatistik 2015," Danish Ministry of Energy, Tech. Rep., Nov 2015.

[9] R.Lund and U. Persson, "Mapping of potential heat sources for heat pumps for district heating in denmark," Energy, vol. 110, pp. 129-138, 2016.
[10] H. Lund, S. Werner, R. Wiltshire, and et al., "4th generation district heating (4gdh): integrating smart thermal grids into future sustainable energy systems," Energy, vol. 68, pp. 1-11, 2014.

[11] “Denmark's energy and climate outlook 2015," Danish Energy Agency, Denmark, Tech. Rep., Dec. 2015.

[12] M. E. Khodayar, L. Wu, and M. Shahidehpour, "Hourly coordination of electric vehicle operation and volatile wind power generation in scuc," IEEE Transactions on Smart Grid, vol. 3, no. 3, pp. 1271-1279, Sept 2012.

[13] K. Knezovic, M. Marinelli, R. J. Møller, P. B. Andersen, C. Træholt, and F. Sossan, "Analysis of voltage support by electric vehicles and photovoltaic in a real danish low voltage network," in 49th International Universities Power Engineering Conference (UPEC), Sept 2014, pp. 16.

[14] S. Martinenas, M. Marinelli, P. Andersen, and C. Træholt, "Evaluation of electric vehicle charging controllability for provision of time critical grid services," in Proceedings of the 51st International Universities Power Engineering Conference. IEEE, 2016.

[15] S. You, J. Hu, A. B. Pedersen, P. B. Andersen, C. N. Rasmussen, and S. Cha, "Numerical comparison of optimal charging schemes for electric vehicles," in 2012 IEEE Power and Energy Society General Meeting, July 2012, pp. 1-6.

[16] J. Hu, S. You, M. Lind, and J. Østergaard, "Coordinated charging of electric vehicles for congestion prevention in the distribution grid," IEEE Transactions on Smart Grid, vol. 5, no. 2, pp. 703-711, March 2014.

[17] "A greener transport system in denmark: environmentally friendly and energy efficient transport," Transportministeriet, Denmark, Tech. Rep., 2012.

[18] H. Lund and W. Kempton, "Integration of renewable energy into the transport and electricity sectors through v2g," Energy Policy, vol. 36 no. 9 , pp. $3578-3587,2008$.

[19] P. Nørgård, "New design methods for energy infrastructures in future urban areas," in 23rd International Conference and Exhibition on Electricity Distribution. Lyon, Frace: CIRED, 2015.

[20] T. Hjøllund, J. Boldt, N. Hendriksen, and P. Nielsen, "Copenhagen, nordhavn implementation plan,” Tech. Rep., Dec. 2014.

[21] Location on middelgrunden shoal wind turbines visualization,middelgrundens vindmøllelaug. Accessed 18/04/2017. [Online]. Available: http://www.middelgrunden.dk/middelgrunden/?q=en/node/35

[22] C. Træholt. Giant battery to charge nordhavn. Accessed 19/04/2017. [Online]. Available: http://www.dtu.dk/english/ news/2017/04/dynamo-giant-battery-to-charge-nordhavn?id= aecdfa56-6888-4868-b9f0-a8345a1ddee4

[23] N. Axholm and M. Soetmann. Sites in nordhavn. Accessed 19/04/2017. [Online]. Available: http://www.byoghavn.dk/english/sales/ sales-nordhavnen-uk.aspx

[24] “The danish transport system," Transportministeriet, Tech. Rep., 2012.

[25] "Fact sheet: The danish motor vehicle taxes," Green Budget Europe Denmark, Tech. Rep., 2016.

[26] U. Agerskov and M. Bisgaard, "Denmark in figures 2016," Statistics Denmark, Tech. Rep., Apr. 2016.

[27] H. Pieper, T. Ommen, W. Markussen, and B. Elmegaard, "Optimal usage of low temperature heat sources to supply district heating by heat pumps," unpublished.

[28] Energinet.dk. Analysis of assumptions. Accessed 24/04/2017. [Online]. Available: http://energinet.dk/EN/El/Udvikling-af-elsystemet/ Analyseforudsaetninger/Sider/default.aspx

[29] When people travel. Accessed 19/04/2017. [Online]. Available: https://www.gov.uk/government/statistical-data-sets/nts05-trips

[30] C. Nielsen. Fuels. Accessed 25/04/2017. [Online]. Available: http://energinet.dk/EN/KLIMA-OG-MILJOE/Miljoerapportering/ Sider/Braendsler-forbrug-og-sammensaetning.aspx

[31] - Electricity generation. Accessed 25/04/2017. [Online]. Available: http://energinet.dk/EN/KLIMA-OG-MILJOE/Miljoerapportering/ Elproduktion-i-anmark/Sider/Elproduktion-i-Danmark.aspx

[32] N. Leaf. Range and charging. Accessed 24/04/2017. [Online]. Available: https://www.nissan.dk/biler/personbiler/leaf/distance-opladning.html

[33] D. Connonlly, "Energyplan cost base," Sustainable Energy Planning Research Group, Aalborg University, Tech. Rep., Jan. 2015.

[34] EnergyPLAN, advanced energy systems analysis computer model, EnergyPLAN Documentation, Jan. 2015.

[35] "Technolofy data for energy plants," Energinet.dk, Tech. Rep., May 2012. 